\title{
158. The Control of Growth and Development in Bombyx mori. XXVIII
}

\section{Light- and Electron-Microscopic Studies on Elementary Neurosecretory Granules Occurring in Nerve Axons between the Brain and the Corpus Allatum or the Suboesophageal Ganglion}

\author{
By Seijiro Morohoshi, *) Tadasu MorI,**) Hiromu AKAI,***) \\ Toshikazu, OshikI,*) Shigeru SATo,****) and Jun ShimadA*)
}

(Comm. by Sajiro Makıno, M. J. A., Dec. 12, 1975)

It was shown that the brain controlled the function of the corpus allatum (CA) and the suboesophageal ganglion (SG) through the nerve commissures from the brain (Br) (Rep. XXI and XXII), and that the brain hormone was released from the $\mathrm{CA}$ and activated the prothoracic glands (PG) (Rep. XXVII). In relation to the function of brain, light- and electron-microscopic examinations were made in this study on the brain-neurosecretory cells (BNC), CA, SG and neurosecretory granules (BNG) occurring in nerve axons between the BNC and the CA or the SG.

Recently, Okajima (unpubl.) observed the nerve axons (RDF.1, MNCC and LNCC) connecting the BNC and the CA, according to the cobalt staining method (Iles and Mulloney, 1971; Pitmann, Tweedle and Cohen, 1972). Waku (1973, personal communication)

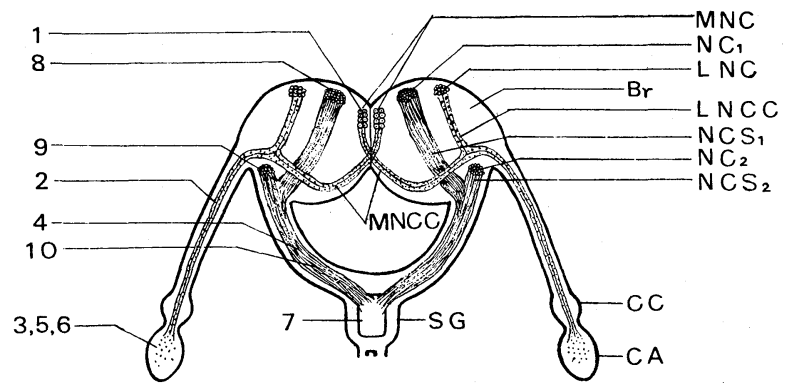

RDF. 1, roughly drawn. Electron (1-6) and light (7-10) microscopically photographed regions and the axons connecting the brain (Br) and the corpus allatum (CA) or the suboesophageal ganglion (SG).

*) Faculty of Agriculture, Tokyo University of Agriculture and Technology, Fuchu-shi, Tokyo 183, Japan.

**) Tokyo Metropolitan Horticultural High School, Setagaya-ku, Tokyo 158.

***) The Sericultural Experiment Station, Suginami-ku, Tokyo 167.

****) Tokyo University of Agriculture, Setagaya-ku, Tokyo 156. 
observed light- and electron-microscopically the nerve axons (RDF. $1, \mathrm{NCS}_{1}$ and $\mathrm{NCS}_{2}$ ) between the brain nerve cells and the SG, and synaptic vesicles in the axon terminal of the $S G$ nerves.

Materials and methods. Eggs of hybrids from J.124 $\times$ C.124, $\mathrm{J} .106 \times \mathrm{Di}$ and $\mathrm{J} .106 \times \mathrm{Kp}$ were incubated at $25^{\circ} \mathrm{C}$ in the light. The fixation and staining for light- and electron-microscopic observations were performed with Akai's method (1971).

Results and discussion. Both the median neurosecretory cells (RDF. 1, MNC and Fig. 1) and the lateral neurosecretory cells (RDF. $1, \mathrm{LNC}$ ) from the 5th instar larvae showed many fine granules. They were again observed in the corpus cardiacum nerves (Fig. 2) and the CA (Fig. 3). These elements may be produced in the neurosecretory cells and released from the CA via the NCC from the neurosecretory cells. It seems probable that in addition to the stimulation due to the neurosecretory hormone there seems to be the nerve stimulation, on account of the fact that synaptic vesicles were demonstrated in the axon terminal of the NCC (Figs. 5-6).

The nerve axons between the brain and the SG come from the nerve cells (RDF. 1, NC $\mathrm{N}_{1}$; Fig. 8) existing between the median and the lateral neurosecretory cells, and also from the nerve cells (RDF. $1, \mathrm{NC}_{2}$; Fig. 9) in the tritocerebrum. These cells, as well as those in the SG nerves (Fig. 4), or in the SG (Fig. 7), showed no such granules. This suggests that the stimulation may be due to the nerve one only.

Acknowledgement. The authors wish to express their thanks to Akira Okajima, Professor of the Yokohama City University, Yokohama, Japan, for unpublished data and for the cobalt staining method.

\section{References}

Akai, H. (1971) : Exptl. Cell Res., 69, 219-223.

Iles, J. F., and Mulloney, B. (1971) : Brain Res., 30, 397-401.

Pitmann, R. M., Tweedle, C. D., and Cohen, M. T. (1972) : Science, 176, 412-415. Sandemann, D. C., and Okajima, A. (1973) : J. Exp. Biol., 59, 17-38.

Waku, Y. (1973): Sci. Res. Minis. Edu. Japan, Agri. Part, 229-230.

Fig. 1. Neurosecretions in the MNC of 6-days-old 5th instar larvae (6/V, J.124 $\times$ c.124). Arrows: elementary neurosecretory granules (ENG), N: nucleus, $\times 15,000$. Fig. 2. Axons and granules in the corpus cardiacum nerves (NCC) $(1 / \mathrm{V}, \mathrm{J} .106 \times \mathrm{Kp})$. Arrows: ENG, ax: axon, $\times 15,000$. Fig. 3. Axons inserted into the basement membrane of the CA (1/IV, J.106 $\times$ Di). Arrows: ENG, ax: axon, $\times 25,000$. Fig. 4. Axons (ax) observed in the $\mathrm{SG}$ nerves $(1 / \mathrm{V}$, J.106 $\times \mathrm{Kp}$ ), $\times 20,000$.

Figs. 5-6. Axons (ax) inserted into the cytoplasm of the CA (1/IV, J.106 $\times$ Di). Arrows: synaptic vesicles, $\times 30,000$. Fig. 7 . Axons (ax) inserted into the SG $(1 / \mathrm{V}, \mathrm{J} .106 \times \mathrm{Di}), \times 480$. Figs. $8-9$. Differential interference contrast micrograph of the $\mathrm{NC}_{1}$ and the $\mathrm{NC}_{2}(1 / \mathrm{V}, \mathrm{J} .106 \times \mathrm{Di}), \times 480$. Fig. 10 . Phase contrast micrograph of the axons (ax) in the SG $(1 / \mathrm{V}, \mathrm{J} .106 \times \mathrm{Di}), \times 480$. 


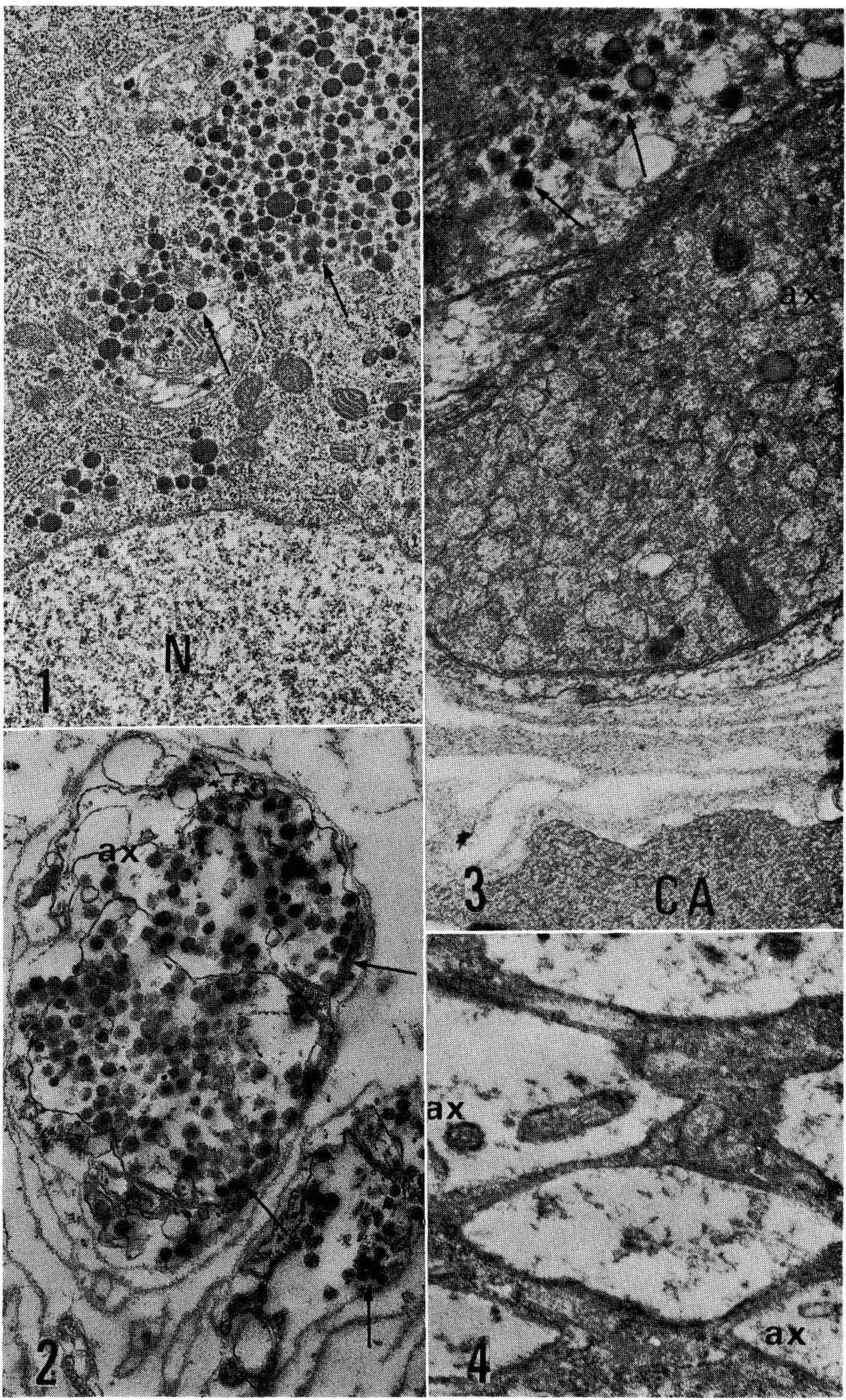

Figs. 1-4 


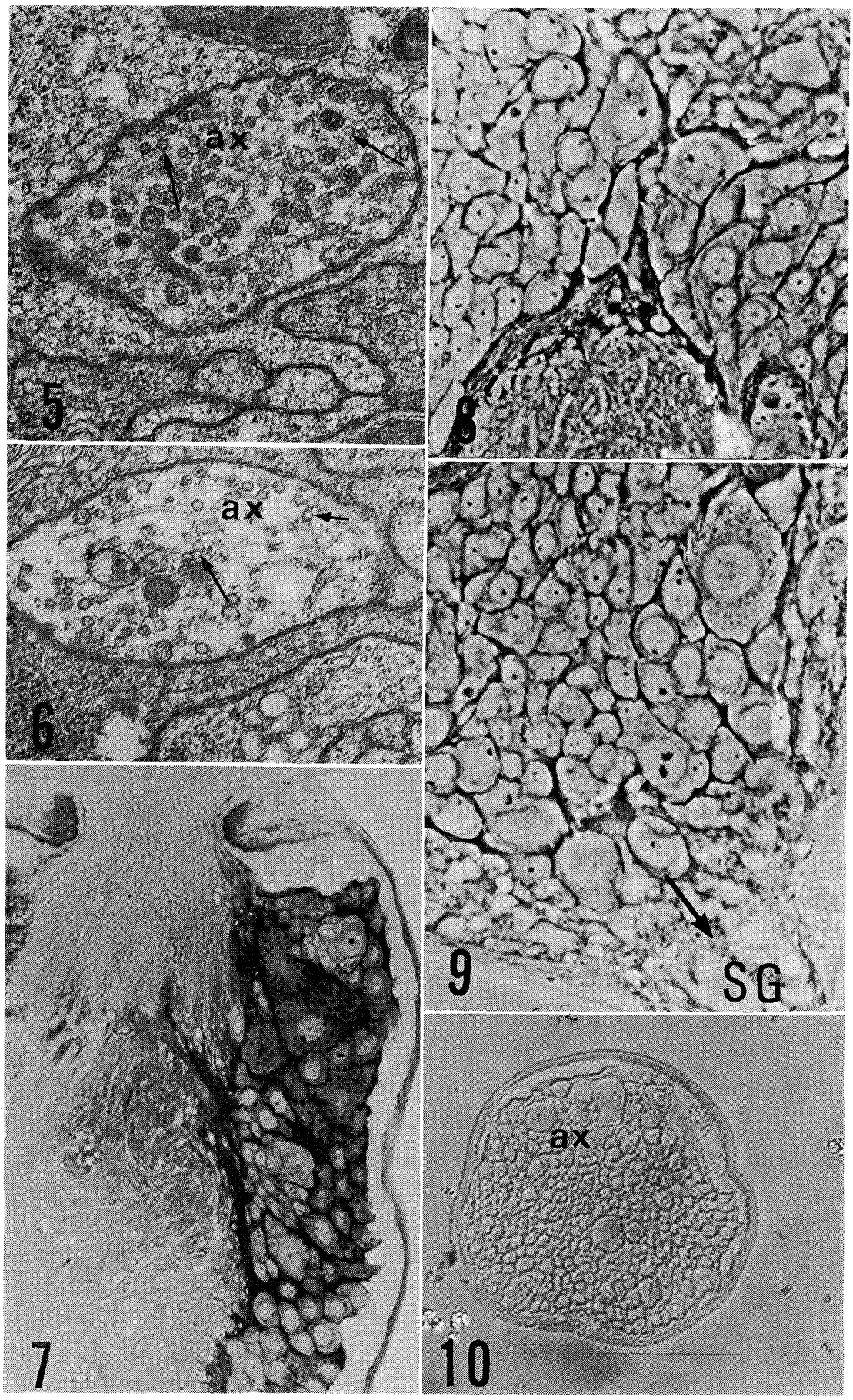

Figs. 5-10 